\title{
Oropharyngeal samples for genotyping and monitoring response to treatment in AIDS patients with Pneumocystis carinii pneumonia
}

\author{
ANTHONY G. TSOLAKI, ROBERT F. MILLER* and ANN E. WAKEFIELD \\ Molecular Infectious Diseases Group, Department of Paediatrics, Institute of Molecular Medicine, John \\ Radcliffe Hospital, Oxford OX3 9DS and *Department of Sexually Transmitted Diseases, Windeyer Institute of \\ Medical Sciences, Royal Free and University College Medical School, London WCIE GAU
}

\begin{abstract}
A nested PCR, amplifying a portion of the gene encoding the mitochondrial large subunit ribosomal RNA (mt LSU rRNA) of Pneumocystis carinii sp. f. hominis was applied to oropharyngeal samples obtained on repeated occasions from $12 \mathrm{HIV}$-infected patients with $P$. carinii pneumonia (PCP) to monitor response to anti- $P$. carinii treatment. Genotyping of $P$. carinii sp. f. hominis was also performed on paired samples of oropharyngeal and broncho-alveolar lavage samples before the start of treatment, and on oropharyngeal samples during the course of treatment, by analysis of sequence variation at the internal transcribed spacer (ITS) regions of the nuclear rRNA operon. When a simple dilutional method was used, a reduction in the amount of amplification product was observed in samples from all patients during the course of treatment. In eight of the 12 patients, a single ITS sequence type was found in the oropharyngeal samples and also in the paired broncho-alveolar lavage sample. A mixed infection was identified in the samples from three patients. In eight patients, the ITS sequence types identified in the oropharyngeal sample were the same as in the broncho-alveolar lavage sample. Nested PCR amplifying the mt LSU rRNA on oropharyngeal samples provides a non-invasive method of monitoring response to treatment of PCP. ITS sequence typing of $P$. carinii sp. f. hominis from oropharyngeal samples appears to be a reliable alternative to broncho-alveolar lavage samples and provides a non-invasive tool for further epidemiological studies.
\end{abstract}

\section{Introduction}

The opportunist fungus Pneumocystis carinii sp. f. hominis is an important cause of pneumonia in immunocompromised individuals, patients receiving immunosuppressive therapy for organ transplantation and patients receiving chemotherapy for the treatment of malignant disease. Despite the widespread availability of highly active antiretroviral therapy and effective regimens of anti- $P$ carinii prophylaxis, $P$. carinii pneumonia (PCP) remains an important cause of respiratory morbidity in individuals with HIV infection, especially in those who are unaware of their HIV serostatus or who are intolerant of, or noncompliant with $P$. carinii prophylaxis or antiretroviral therapy. As immunosuppressed patients with PCP

Received 12 Oct. 1998; revised version received 30 Jan. 1999; accepted 9 Feb. 1999.

Corresponding author: Dr A. E. Wakefield (e-mail: wakefiel @,worf.molbiol.ox.ac.uk). rarely produce sputum, and the diagnostic yield from spontaneously expectorated sputum is low for $P$. carinii [1], diagnosis has relied on histochemical or immunofluorescence staining of respiratory secretions obtained by the invasive techniques of hypertonic saline induced sputum, or bronchoscopic alveolar lavage (BAL) $[2,3]$.

The application of molecular diagnostic techniques to BAL fluid [4] or induced sputum [5] has demonstrated that DNA amplification has a higher sensitivity than conventional staining for detection of $P$. carinii sp. $\mathrm{f}$. hominis. Oropharyngeal (OP) samples, obtained by simple rinsing of the mouth, provide an alternative non-invasive sample. A preliminary study has shown that $P$. carinii sp. f. hominis DNA can be detected in $78 \%$ of OP samples from HIV-infected persons with PCP by the PCR with oligoblotting, with primers designed to the mitochondrial large subunit ribosomal RNA (mt LSU rRNA) gene [6]. A single round of touchdown PCR at the same locus has also been shown to be effective in the diagnosis of PCP in OP samples 
$[7,8]$. A nested PCR at the mt LSU rRNA has now been developed, based on the original primers pAZ102$\mathrm{H}$ and pAZ102-E [4-6, 9] with internal primers pAZ102-X and pAZ102-Y, which has an improved sensitivity for the detection of $P$. carinii sp. f. hominis. This is able to detect one or two organisms $[10,11]$, and has been applied successfully to OP samples [12].

Differences among isolates of $P$. carinii sp. f. hominis have been demonstrated by identification of DNA polymorphisms at a number of loci. At a portion of the mt LSU rRNA gene, two single base polymorphisms have been identified with five different types of $P$. carinii sp. f. hominis [11, 13-15]; at the 5-enolpyruvyl shikimate-3-phosphate synthase domain of the arom locus, two single-base polymorphisms have been observed, resulting in four different types [11, 16]. Variations at the internal transcribed spacer (ITS) regions of the nuclear RNA operon of $P$. carinii sp. f. hominis have been found to be more informative and have been used to develop a method of typing isolates of $P$. carinii sp. f. hominis $[11,17-24]$. To date, BAL fluid or lung biopsy material has been used to obtain isolates of $P$. carinii sp. f. hominis for typing.

In this study, a nested PCR with primers to the mt LSU RNA was applied to OP samples, obtained on repeated occasions from HIV-infected persons with PCP to monitor response to treatment. The $P$. carinii sp. f. hominis detected in the OP samples were typed by analysis of sequence variations at the ITS regions.

\section{Materials and methods}

\section{Patients}

A total of 12 patients was studied prospectively; all were HIV-1 antibody-positive homosexual men admitted to the specialist HIV/AIDS Unit, Middlesex Hospital Site, University College London Hospitals Trust, for investigation of respiratory symptoms. A diagnosis of PCP was made on the basis of typical clinical presentation and positive histochemical staining of BAL fluid from 11 patients (patients $1-3$ and 5-12) and hypertonic saline-induced sputum from one patient (patient 4), with Grocott's methenamine silver stain. All fibreoptic bronchoscopies were done by one respiratory physician (RFM) by a technique described previously [25]. Sputum induction was as described previously [25]. At the time of bronchoscopy a 10-ml portion of BAL fluid was saved, frozen immediately after collection and stored at $-20^{\circ} \mathrm{C}$ before analysis.

The CD4 lymphocyte count and previous prophylaxis against $P$. carinii for each patient were recorded at presentation. The disease severity (Table 1) was assessed by means of the arterial oxygen tension (measured with the patient breathing room air; the lower the arterial oxygen tension, the more severe the pneumonia) and the degree of chest radiographic abnormalities by a scoring system as described previously [6]. Co-pathogens were identified in the BAL fluid from two patients, patient 6 had Streptococcus pneumoniae which was treated with oral

Table 1. Patient characteristics, disease severity and treament of PCP

\begin{tabular}{|c|c|c|c|c|c|c|c|}
\hline \multirow[b]{2}{*}{$\begin{array}{l}\text { Patient } \\
\text { no. }\end{array}$} & \multirow[b]{2}{*}{$\begin{array}{l}\text { Sample } \\
\text { code }\end{array}$} & \multirow[b]{2}{*}{ Prophylaxis } & \multirow[b]{2}{*}{$\begin{array}{l}\text { Episode } \\
\text { of PCP }\end{array}$} & \multirow{2}{*}{$\begin{array}{c}\text { CD4 } \\
\text { count } \\
\left(\times 10^{6} / \mathrm{L}\right)\end{array}$} & \multicolumn{2}{|c|}{ Disease severity } & \multirow[b]{2}{*}{$\begin{array}{l}\text { Treatment } \\
\text { drug/route/duration }\end{array}$} \\
\hline & & & & & $\begin{array}{l}\mathrm{PaO}_{2} \\
(\mathrm{kPa})\end{array}$ & $\begin{array}{l}\text { Chest } \\
\text { X-ray score }\end{array}$ & \\
\hline 1 & $\mathrm{H} 32$ & Nil & 1 & 30 & 9.5 & 2 & $\begin{array}{l}\text { TMP } / \text { SMX iv }(\mathrm{d} 1-\mathrm{d} 13) \rightarrow \text { TMP } / \text { SMX po } \\
(\mathrm{d} 14-\mathrm{d} 21)\end{array}$ \\
\hline 2 & H15 & Dapsone & 1 & 100 & 9.6 & 2 & Pent iv $(\mathrm{d} 1-\mathrm{d} 8) \rightarrow$ pent neb $(\mathrm{d} 9-\mathrm{d} 21)$ \\
\hline 3 & $\mathrm{H} 33$ & Nil & 1 & 90 & 6.9 & 3 & $\begin{array}{l}\text { TMP } / \text { SMX iv }(\mathrm{d} 1-\mathrm{d} 9) \rightarrow \text { clin } / \text { prim po } \\
(\mathrm{d} 10-\mathrm{d} 14) \rightarrow \text { atovaquone on }(\mathrm{d} 15-\mathrm{d} 21) \\
\text { methylprednisolone iv }(\mathrm{d} 1-\mathrm{d} 5) \rightarrow \\
\text { prednisolone po }(\mathrm{d} 6-\mathrm{d} 15)\end{array}$ \\
\hline 4 & $\mathrm{H} 27$ & Nil & 1 & 20 & 11.9 & 2 & Pent iv $(\mathrm{d} 1-\mathrm{d} 5) \rightarrow$ clin/prim po $(\mathrm{d} 6-\mathrm{d} 21)$ \\
\hline 5 & $\mathrm{H} 10$ & Nil & 1 & 310 & 8.6 & 3 & $\begin{array}{l}\text { TMP /SMX iv }(\mathrm{d} 1-\mathrm{d} 8) \rightarrow \mathrm{clin} / \mathrm{prim} \text { iv } / \text { po } \\
(\mathrm{d} 9-\mathrm{d} 14) \rightarrow \text { iv neb }(\mathrm{d} 15-\mathrm{d} 21) \\
\text { methylprednisolone iv }(\mathrm{d} 1-\mathrm{d} 5) \rightarrow \\
\text { prednisolone po }(\mathrm{d} 6-\mathrm{d} 15)\end{array}$ \\
\hline 6 & $\mathrm{H} 28$ & Dapsone & 1 & 80 & 11.0 & 2 & $\begin{array}{l}\text { Pent iv }(\mathrm{d} 1-\mathrm{d} 5) \rightarrow \text { clin/prim po } \\
(\mathrm{d} 6-\mathrm{d} 16) \rightarrow \text { atovaquone po }(\mathrm{d} 17-\mathrm{d} 21)\end{array}$ \\
\hline 7 & $\mathrm{H} 22$ & Neb pent & 2 & 70 & 10.2 & 2 & $\begin{array}{l}\text { Clin/prim iv/po }(\mathrm{d} 1-\mathrm{d} 14) \rightarrow \text { clin/prim po } \\
(\mathrm{d} 15-\mathrm{d} 21) \text { methylprednisolone iv } \\
(\mathrm{d} 4-\mathrm{d} 8) \rightarrow \text { prednisolone po }(\mathrm{d} 9-\mathrm{d} 15)\end{array}$ \\
\hline 8 & $\mathrm{H} 23$ & Neb pent & 3 & 60 & 11.3 & 2 & Atovaquone po $(\mathrm{d} 1-\mathrm{d} 21)$ \\
\hline 9 & H6 & TMP/SMX & 1 & 20 & 8.6 & 3 & $\begin{array}{l}\text { TMP/SMX iv }(\mathrm{d} 1-\mathrm{d} 14) \rightarrow \text { TMP/SMX po } \\
(\mathrm{d} 15-\mathrm{d} 21)\end{array}$ \\
\hline 10 & $\mathrm{H} 43$ & Nil & 1 & 30 & 8.3 & 2 & $\begin{array}{l}\text { TMP/SMX iv }(\mathrm{d} 1-\mathrm{d} 11) \rightarrow \text { TMP } / \text { SMX po } \\
(\mathrm{d} 12-\mathrm{d} 21) \text { methylprednisolone iv }(\mathrm{d} 1-\mathrm{d} 3)\end{array}$ \\
\hline 11 & $\mathrm{H} 44$ & Neb pent & 1 & 10 & 8.1 & 3 & $\begin{array}{l}\text { Clin/prim iv/po }(\mathrm{d} 1-\mathrm{d} 10) \rightarrow \text { clin/prim po } \\
(\mathrm{d} 11-\mathrm{d} 21) \text { methylprednisolone iv } \\
(\mathrm{d} 1-\mathrm{d} 5) \rightarrow \text { prednisolone po }(\mathrm{d} 6-\mathrm{d} 15)\end{array}$ \\
\hline 12 & H34 & Dapsone & 1 & 50 & 9.2 & 2 & Pent iv $(\mathrm{d} 1-\mathrm{d} 8) \rightarrow$ clin/prim po $(\mathrm{d} 9-\mathrm{d} 21)$ \\
\hline
\end{tabular}

$\rightarrow$, treatment changed (because of adverse reaction, not failure to respond); iv, intravenous; po, by mouth; TMP/SMX, trimethoprim/sulphamethoxazole; pent, pentamidine; neb, nebulised; clin, clindamycin; prim, primaquine; d, day. Chest X-ray score: 0, normal; 1, subtle increased perihilar interstitial markings; 2, more prominent interstitial markings, extending laterally, without evidence of alveolar infiltrates; 3 , gross interstitial infiltrates with mild aveolar infiltrates; 4 , extensive interstitial and alveolar infiltrates. 
erythromycin and patient 8 had Haemophilus influenzae which was treated with oral amoxycillin. Cotrimoxazole (trimethoprim/sulphamethoxazole, TMP/ SMX) was the preferred treatment unless patients had a previous history of adverse reactions to these agents, in which case alternative therapies were used according to a unit protocol [26]. In patients with an arterial oxygen tension $<9.3 \mathrm{kPa}$ breathing room air, adjuvant glucocorticoids were given, following published guidelines [27]. Response to treatment was assessed by defervescence and improvements in tachypnoea, dyspnoea and arterial oxygenation. When treatment was changed, it was because of adverse reaction to therapy and not because of treatment failure. Finally, use of secondary prophylaxis was recorded and patients were followed up for 6 months after their recovery from PCP.

Before treatment began, OP samples were obtained from each patient as described previously [6]. In summary, patients gargled and rinsed out their mouth with $10 \mathrm{ml}$ of sterile saline $0.9 \%$. Further OP samples were obtained from each patient, where possible on a daily basis, until they were discharged from hospital. Consecutive daily samples were not obtained in all patients for several reasons. Some patients declined repeat sampling on some days but not on others, some patients were temporarily absent from the ward (e.g., for weekend leave) and others were well enough to be managed as outpatients and, therefore, returned to the ward for monitoring only intermittently or when they developed adverse drug reactions and required change of therapy and close monitoring. On each occasion, samples were obtained in the morning, where possible soon after the patient had awoken and before they had brushed their teeth and eaten breakfast. The OP samples were frozen immediately and stored at $-20^{\circ} \mathrm{C}$. OP samples were obtained before bronchoscopy or sputum induction on the days these procedures were performed. The BAL fluid and OP samples were coded and all analyses were done blind to the clinical details.

\section{$P C R$ detection of $P$. carinii}

The OP samples $(4 \mathrm{ml})$ were centrifuged at $12000 \mathrm{~g}$ for $5 \mathrm{~min}$ and the pellets were recovered. DNA was extracted from the $\mathrm{OP}$ pellets and the BAL samples $(0.5 \mathrm{ml})$ [12]. The presence of $P$. carinii in the OP samples was detected with a nested PCR at the mt LSU rRNA, with primers pAZ102-H and pAZ102-E in the first round amplification followed by $\mathrm{pAZ102-X}$ and $\mathrm{pAZ102}-\mathrm{Y}$ in the second round amplification as described previously $[10,11]$. Taq DNA polymerase (Promega, Southampton) was used throughout the study. Serial five-fold dilutions of the sample DNA were used in each PCR experiment and an approximate estimation of the $P$. carinii sp. f. hominis load in each sample was obtained. Negative controls were included in each experiment in both DNA extraction and amplification, to monitor for possible contamination. DNA extraction and PCR were performed in a laminar flow cabinet and disposable tips, tubes and reagent aliquots were used to avoid contamination. A sample of P. carinii sp. f. hominis DNA, obtained from a patient with histologically confirmed PCP, was used as a positive control in each experiment.

\section{P. carinii ITS sequence typing}

DNA amplification at the ITS regions was performed on OP and BAL samples by a nested PCR, with NITSF and NITSR in the first round amplification and ITSF3/RI and ITS2R3/RI in the second round amplification, as described previously $[11,20]$. The primer pair N18SF (5'-GGTCTTCGGACTGGCAGC$\left.3^{\prime}\right)$ and N26SRX (5'-TTACTAAGGGAATCCTTGTTA$\left.3^{\prime}\right)$ were subsequently used as first round primers in 10 samples and showed greater specificity for $P$. carinii sp. f. hominis. Amplification products were either sequenced directly by cycle sequencing with radiolabelled terminators (Thermo Sequenase cycle sequencing kit, Amersham), or cloned and sequenced by conventional or automated sequencing. Amplification products were sequenced directly by cycle sequencing with the primers 5.8S-ITS1RX (5'-CAATTCACACTACTTATCGCA-3'), 5.8S-ITS2FX (5'-GCAGAATTTAGTGAATCATCG-3') and ITS1HPT (5'AAAAAAAAATTCACAGATGTTTGA- $3^{\prime}$ ). When an unambiguous sequence was obtained, the ITS type was assigned to the sample. In samples in which the sequence was not definitive, suggesting the presence of more than one type of $P$. carinii sp. f. hominis, the amplification products were cloned and the sequence of four clones was determined by either conventional or automated sequencing. Some samples were analysed by both methods to confirm the validity of the methods. The BAL samples from patients 3,6 and 12 were sequenced directly, those from patients $2,5,7$ and 9 were cloned and then sequenced, and those from patients 1 and 10 were analysed by both methods. The OP samples from patient 4 were sequenced directly, those from patients $1,2,3,5$ and 11 were cloned and then sequenced, and those from patients $6,7,8,9,10$ and 12 were analysed by both methods.

\section{Results}

\section{$P$. carinii sp. $f$. hominis load in patients receiving anti-P. carinii therapy}

Sequential OP samples were obtained from $12 \mathrm{HIV}$ infected patients with confirmed PCP who were receiving treatment for pneumonia. An OP sample was taken from each patient before the start of treatment and before bronchoscopy (day 1). A BAL sample with obtained from 11 of the 12 patients $1-3$ days later. Further OP samples were taken from each patient at intervals for a period of $8-24$ days. The 
number of OP samples analysed for each patient ranged from six to 14 (Fig. 1).

Nested PCR at the mt LSU rRNA, with serial dilutions of each sample was used to assess the $P$. carinii load in each sample. This PCR has previously been shown to be specific for $P$. carinii and to have a high level of sensitivity because of the presence of multiple copies of the mitochondrial genome/organism [4-6, 28-35]. $P$. carinii DNA was detected in the samples taken before the start of treatment (day 1) from all the patients (Fig. 1). The approximate amount of $P$. carinii DNA in each OP sample was estimated, and showed a high level of amplification product in the samples from all the patients at day 1 , which was still present at day 3 (Fig. 1). Fluctuations in the amount of amplification product, resulting in an overall reduction, were observed in samples from all patients during the course of their treatment. An overall reduction was detected by day 7 in one of the patients (patient 1), by day 14 in a further five (patients 2, 3, 4, 5 and 6) and in all patients by day 21 (Fig. 1 and Table 2). In four of the samples (from patients 4, 8, 9 and 10), $P$. carinii DNA was detected in the final OP sample collected, on days 9 , 15,16 and 17, respectively. Therefore, in these patients it was not possible to assess the time point at which $P$. carinii could no longer be detected. After recovery from PCP, all patients began secondary prophylaxis. No patient developed recurrent PCP during the 6-months follow-up period.

\section{P. carinii sp. $f$. hominis ITS sequence types from paired $O P$ and BAL samples}

The ITS sequence type of $P$. carinii sp. f. hominis extracted from paired $\mathrm{OP}$ and BAL samples was determined in 11 of the 12 patients (bronchoscopy was not performed on patient 4). The OP sample was taken before the start of treatment (day 1) and before the BAL sample. A single BAL sample was taken from 11 patients (an IS sample was taken from patient 4) 13 days later for diagnostic purposes, and subsequently used for ITS sequence typing (Table 2). Previous studies have reported 13 different ITS sequence types $[11,20]$. In this study, a total of five ITS1 types and nine ITS2 types were observed, resulting in a total of 15 ITS sequence types, of which 10 are new to this study (Miller, Tsolaki and Wakefield, unpublished observations). In eight of the patients (patients 3, 5$8,10-12$ ) a single ITS sequence type was observed in the OP sample at day 1 . This same ITS sequence type was also detected in the BAL sample, as a single type
(Table 2). In patient 9, two ITS sequence types were found in the OP sample $\left(B_{1} a_{3}, B_{1} c_{1}\right)$ and only one of these types $\left(B_{1} a_{3}\right)$ was found in the BAL sample taken 3 days later. In two patients (patients 1 and 2) more than one ITS sequence type was detected in the BAL and the OP samples. In patient 1 , two ITS types $\left(B_{1} a_{1}\right.$ and $B_{2} a_{3}$ ) were observed in the OP sample at day 1 , and on day 3 of treatment, a mixture of ITS types was observed in both the OP and BAL samples. In patient 2 , four ITS types $\left(B_{1} e_{1}, B_{1} a_{1}, B_{2} a_{1}, B_{2} a_{3}\right)$ were observed in the OP sample on day 1 , and four ITS types $\left(B_{1} e_{1}, B_{1} e_{3}, B_{1} a_{3}, B_{2} a_{2}\right)$ in the BAL sample taken on day 2 of treatment. ITS type $B_{1} e_{1}$ was present in both these samples (Table 2).

\section{$P$. carinii sp. $f$. hominis ITS sequence types in sequential $O P$ samples during anti-P. carinii therapy}

The ITS sequence type was determined in the OP sample at the final time point for which PCR at the ITS locus yielded a positive amplification product. In four of the 12 patients, the ITS sequence type was determined in the final OP sample in which $P$. carinii DNA was detected by PCR at the mtLSU rRNA locus. However, in eight of the patients the study failed to amplify $P$. carinii DNA by the ITS PCR in samples in which PCR at the mt LSU rRNA gene was positive. PCR at the mt LSU rRNA was more sensitive than at the ITS regions. ITS PCR was attempted on multiple OP samples from these patients, and the latest sample during the course of treatment at which an amplification product was obtained was used for typing. This ranged from day 3 (patient 1) to day 15 (patient 12) (Fig. 1 and Table 2).

A single ITS sequence type was found at the final time point for which PCR at the ITS locus yielded a positive amplification product in the sample from 10 of the patients. In nine of these (patients 3-8, 10-12), a single ITS sequence type was also found in the OP sample before the start of treatment (day 1). In the samples from these nine patients, the same ITS sequence type was found at day 1 , in the sample taken before the start of treatment, and during the course of treatment. In three of the patients (patients 1,2 and 9) more than one ITS sequence type was found in the OP sample taken before the start of treatment. In patient 9 , two types were found in the OP sample $\left(B_{1} a_{3}, B_{1} c_{1}\right)$ taken before the start of treatment, and only one of these $\left(B_{1} a_{3}\right)$ was found in the BAL sample taken 3

Fig. 1. $P$. carinii sp. f. hominis amplification product in sequential OP samples, taken from day 1 up to day 25 , from 12 patients receiving anti- $P$. carinii therapy.,$+++ P$. carinii $\mathrm{sp}$. f. hominis amplification product detectable at neat, 5- and -25 -fold dilution of sample;,$++ P$. carinii sp. f. hominis amplification product detectable at neat and 5 -fold dilution of sample;,$+ P$. carinii sp. f. hominis amplification product detectable in neat sample; 0 , no detectable $P$. carinii sp. $\mathrm{f}$. hominis amplification product. $\mathbf{a}$, days on which $P$. carinii sp. f. hominis amplification product was detected; $\square$, days on which samples were tested but no $P$. carinii sp. f. hominis amplification product was detected; $\mathbf{m}$, days on which samples also underwent ITS sequence typing. 

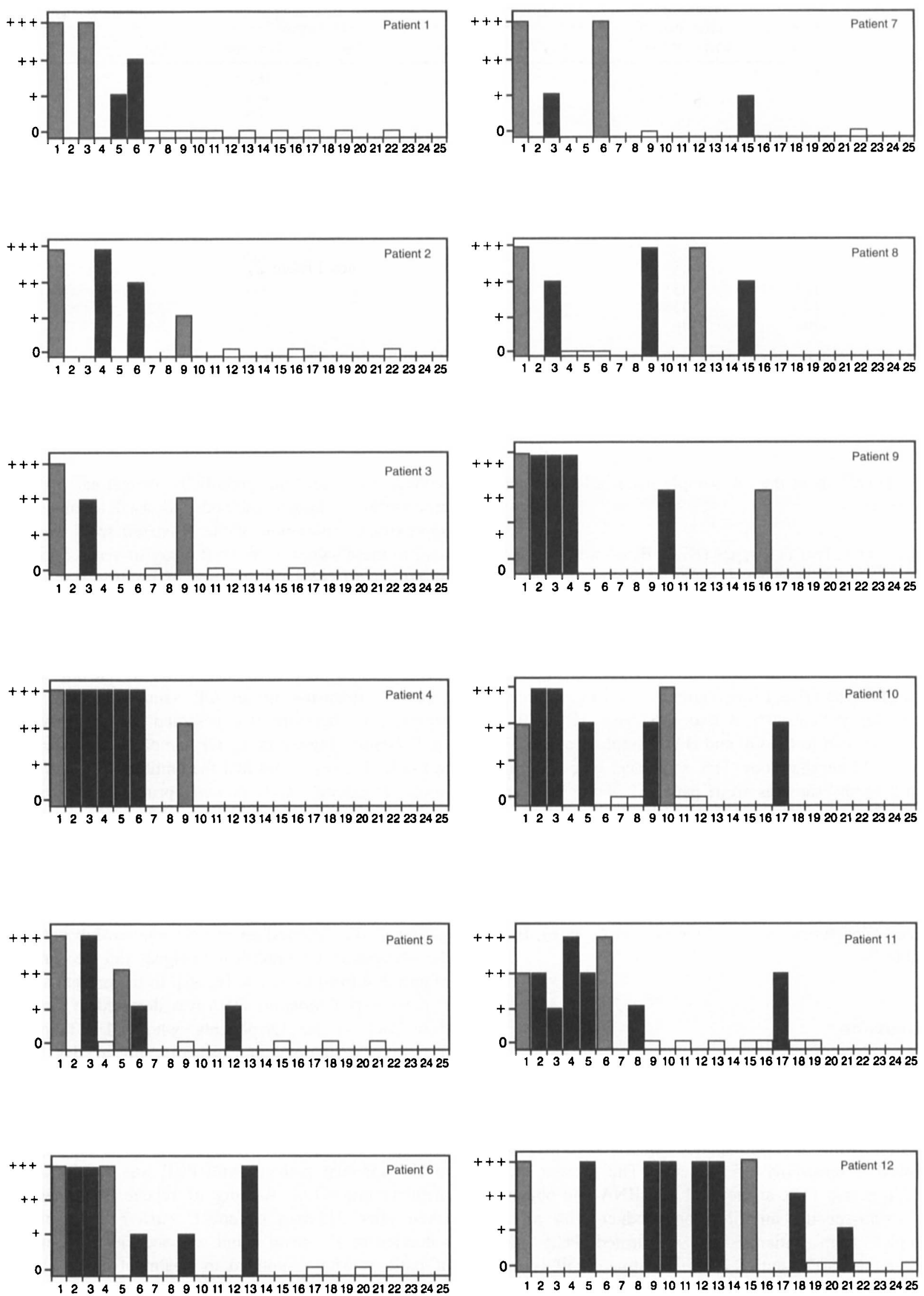
Table 2. ITS sequence typing of $P$. carinii sp. f. hominis from OP and BAL samples

\begin{tabular}{|c|c|c|c|c|c|c|c|c|}
\hline \multirow{2}{*}{$\begin{array}{l}\text { Patient } \\
\text { no. }\end{array}$} & \multirow{2}{*}{$\begin{array}{l}\text { Sample } \\
\text { code }\end{array}$} & \multirow{2}{*}{$\begin{array}{l}\text { Last detectable } \\
\text { DNA signal } \\
\text { after start of } \\
\text { treatment (days) }\end{array}$} & \multicolumn{2}{|c|}{$\begin{array}{l}\text { OP sample at } \\
\text { start of episode }\end{array}$} & \multicolumn{2}{|c|}{ BAL sample } & \multicolumn{2}{|c|}{$\begin{array}{c}\text { OP sample } \\
\text { during treatment }\end{array}$} \\
\hline & & & Day & ITS type & Day & ITS type & Day & ITS type \\
\hline 1 & H32 & 6 & 1 & $\begin{array}{l}\mathrm{B}_{1} \mathrm{a}_{1} \\
\mathrm{~B}_{2} \mathrm{a}_{3}\end{array}$ & 3 & $\begin{array}{l}B_{1} a_{1} \\
B_{1} a_{3} \\
B_{2} a_{1}\end{array}$ & 3 & $\begin{array}{l}\mathrm{B}_{1} \mathrm{a}_{1} \\
\mathrm{~B}_{1} \mathrm{a}_{3} \\
\mathrm{~B}_{1} \mathrm{a}_{2} \\
\mathrm{~B}_{4} \mathrm{a}_{3}\end{array}$ \\
\hline 2 & H15 & 9 & 1 & $\begin{array}{l}\mathrm{B}_{1} \mathrm{e}_{1} \\
\mathrm{~B}_{1} \mathrm{a}_{1} \\
\mathrm{~B}_{2} \mathrm{a}_{1} \\
\mathrm{~B}_{2} \mathrm{a}_{3}\end{array}$ & 2 & $\begin{array}{l}\mathrm{B}_{1} \mathrm{e}_{1} \\
\mathrm{~B}_{1} \mathrm{e}_{3} \\
\mathrm{~B}_{1} \mathrm{a}_{3} \\
\mathrm{~B}_{2} \mathrm{a}_{2}\end{array}$ & 9 & $\begin{array}{l}\mathrm{B}_{1} \mathrm{e}_{1} \\
\mathrm{~B}_{1} \mathrm{e}_{2} \\
\mathrm{~B}_{5} \mathrm{a}_{3}\end{array}$ \\
\hline 3 & H33 & 9 & 1 & $\mathrm{~B}_{1} \mathrm{~b}_{1}$ & 4 & $\mathrm{~B}_{1} \mathrm{~b}_{1}$ & 9 & $B_{1} b_{1}$ \\
\hline 4 & $\mathrm{H} 27$ & 9 & 1 & $\mathrm{~B}_{1} \mathrm{~b}_{1}$ & - & - & 9 & $\mathrm{~B}_{1} \mathrm{~b}_{1}$ \\
\hline 5 & $\mathrm{H} 10$ & 12 & 1 & $\mathrm{~B}_{2} \mathrm{a}_{5}$ & 4 & $\mathrm{~B}_{2} \mathrm{a}_{5}$ & 5 & $\mathrm{~B}_{2} \mathrm{a}_{5}$ \\
\hline 6 & $\mathrm{H} 28$ & 13 & 1 & $\mathrm{~B}_{2} \mathrm{a}_{1}$ & 3 & $\mathrm{~B}_{2} \mathrm{a}_{1}$ & 4 & $B_{2} a_{1}$ \\
\hline 7 & $\mathrm{H} 22$ & 15 & 1 & $\mathrm{~B}_{2} \mathrm{a}_{1}$ & 2 & $\mathrm{~B}_{2} \mathrm{a}_{1}$ & 6 & $\mathrm{~B}_{2} \mathrm{a}_{1}$ \\
\hline 8 & $\mathrm{H} 23$ & 15 & 1 & $\mathrm{~B}_{2} \mathrm{a}_{1}$ & 2 & $\mathrm{~B}_{2} \mathrm{a}_{1}$ & 12 & $\mathrm{~B}_{2} \mathrm{a}_{1}$ \\
\hline 9 & H6 & 16 & 1 & $\begin{array}{l}\mathrm{B}_{1} \mathrm{a}_{3} \\
\mathrm{~B}_{1} \mathrm{c}_{1}\end{array}$ & 4 & $\mathrm{~B}_{1} \mathrm{a}_{3}$ & 16 & $\mathrm{~B}_{1} \mathrm{a}_{3}$ \\
\hline $10^{*}$ & $\mathrm{H} 43$ & 17 & 1 & $\mathrm{~B}_{1} \mathrm{a}_{3}$ & 3 & $\mathrm{~B}_{1} \mathrm{a}_{3}$ & 10 & $\mathrm{~B}_{1} \mathrm{a}_{3}$ \\
\hline 11 & $\mathrm{H} 44$ & 17 & 1 & $\mathrm{~B}_{1} \mathrm{a}_{3}$ & 2 & $B_{1} a_{3}$ & 6 & $\mathrm{~B}_{1} \mathrm{a}_{3}$ \\
\hline 12 & H34 & 21 & 1 & $\mathrm{~A}_{4} \mathrm{a}_{3}$ & 2 & $\mathrm{~A}_{4} \mathrm{a}_{3}$ & 15 & $\mathrm{~A}_{4} \mathrm{a}_{3}$ \\
\hline
\end{tabular}

${ }^{*}$ Patient 10 - additional OP samples during treatment: day 2 , ITS type $B_{1} a_{3}$; day 3 , ITS type $B_{1} a_{3}$.

days later, and in the OP sample taken after treatment for 16 days.

In patient 1 , two ITS types $\left(\mathrm{B}_{1} \mathrm{a}_{1}, \mathrm{~B}_{2} \mathrm{a}_{3}\right)$ were observed in the OP sample at day 1 . After treatment for 3 days, a mixture of ITS types was detected in both the OP and BAL samples; four ITS types were detected in the OP sample $\left(B_{1} a_{1}, B_{1} a_{3}, B_{1} a_{2}, B_{4} a_{3}\right)$ whilst three ITS types were observed in the BAL sample $\left(B_{1} a_{1}, B_{1} a_{3}, B_{2} a_{1}\right)$. One ITS type $\left(B_{1} a_{1}\right)$ was common to all three samples from this patient, whilst two ITS types $\left(B_{1} a_{3}, B_{1} a_{1}\right)$ were common to the OP and BAL samples collected on day 3. More than one ITS sequence type was also found in the samples from patient 2. Four ITS types $\left(B_{1} e_{1}, B_{1} a_{1} B_{2} a_{1}, B_{2} a_{3}\right)$ were detected in the OP sample taken before the start of treatment and four ITS types $\left(B_{1} e_{1}, B_{1} e_{3}, B_{1} a_{3}, B_{2} a_{2}\right)$ were detected in the $B A L$ sample taken on day 2 of treatment. ITS type $B_{1} e_{1}$ was present in both these samples and again on day 9 , when three ITS types were observed $\left(B_{1} e_{1}, B_{1} e_{2}, B_{5} a_{3}\right)$ (Table 2).

\section{Discussion}

An earlier study demonstrated the utility of OP samples in the detection of $P$. carinii sp. f. hominis, by a single round of PCR at the mt LSU rRNA followed by probing with a radiolabelled oligonucleotide, and showed a sensitivity of $78 \%$ [6]. The present study used a nested PCR at the mt LSU rRNA and obtained $P$. carinii-specific amplification product with all the samples from patients with confirmed PCP, taken before the start of anti- $P$. carinii treatment. OP samples have been shown to be effective for the diagnosis of PCP [6-8, 12]. This study demonstrated the value of these samples in epidemiological studies, as multiple, sequential samples can be obtained from patients without the need for potentially dangerous invasive procedures. A simple method was used to obtain an approximate estimation of the $P$. carinii sp. f. hominis load in these samples, by PCR assay of serial dilutions of extracted DNA. A diminution of amplification signal with time during the course of therapy was demonstrated, which was an indication of the relative amounts of $P$. carinii sp. f. hominis in the samples. The earlier study showed that there are fewer $P$. carinii sp. f. hominis organisms in an $\mathrm{OP}$ sample than a BAL sample [6]. Therefore, it is assumed that the $P$. carinii sp. f. hominis burden in the OP sample reflects the load in the BAL sample, but that the number of $P$. carinii is lower. $P$. carinii sp. f. hominis primarily infects the alveolar spaces, with only low numbers of organisms in upper respiratory tract samples (particularly OP samples), undetectable by microscopy but detectable by PCR.

Earlier studies showed an inverse relationship between the strength of the amplification signal and the duration of anti- $P$. carinii treatment $[6,30]$. In the present study, $P$. carinii $\mathrm{sp}$. f. hominis DNA was detected in samples from each of the 12 patients, who had a range of disease presentations and severity, up to day 6 of treatment. The reduction in the $P$. carinii sp. f. hominis load in the OP samples correlated with the clinical improvements of the patients. This is consistent with findings from a previous study in which $P$. carinii load in HIV-infected patients with PCP was monitored by methenamine silver staining of repeat BAL samples taken after 21 days of anti- $P$. carinii treatment. A reduction in $P$. carinii count was seen in the majority of patients who responded to treatment and who did not relapse. In contrast, no reduction in $P$. carinii count was observed in some clinical responders. The majority of these patients had a poor outcome, with a relapse of $P$. carinii pneumonia within 6 months [36]. 
Determination of the $P$ carinii load by DNA amplification rather than methenamine silver staining may result in a more accurate estimate of the number of viable $P$. carinii sp. f. hominis organisms in a sample. DNA from all life-cycle stages of the organism is detected by PCR, whereas methenamine silver staining only visualises the cystic phase of the organism, and does not distinguish between viable organisms and the cell wall of empty, non-viable cysts. However, the results of the present study suggest that the quality of the OP samples may fluctuate to some extent. This is to be expected, as $P$. carinii sp. f. hominis is primarily present as an alveolar infection and many factors such as variablity in cough and the effectiveness of the muco-ciliary escalator will influence the number of organisms in an OP sample. In a few patients, consecutive samples showed fluctuations between positive and negative results, before being consistently negative for $P$. carinii sp. f. hominis. The inclusion of numerous controls in each experiment ensured that this fluctuation was not due to contamination, but was a true reflection of the parasite load in these upper respiratory tract samples. Despite these technical complications, the results show that OP samples provide useful non-invasive specimens for epidemiological studies on $P$. carinii sp. f. hominis.

Although $P$. carinii sp. f. hominis DNA was detected in the last available sample in four of the 12 patients in this study, all the patients recovered from their pneumonia and none had another episode of PCP in the following 6 months. Patient 11 had a further episode of PCP 7 months later. Further studies are now in progress, applying this methodology to samples from patients who failed to respond to treatment, patients who initially responded and then deteriorated towards the end of their course of treatment, and patients who responded yet underwent an early relapse.

These data demonstrate that detection of $P$ carinii sp. f. hominis by nested PCR at the ITS regions was less sensitive than nested PCR at the mt LSU rRNA. ITS sequence genotyping was possible in only four of the 12 patients at the final time point at which the mt LSU rRNA PCR was positive. The most plausible explanation for this finding is the copy number of the two genes, the mitochondrial genome being present in many copies within each organism, whereas the nuclear-encoded ITS regions of the rRNA operon are thought to be present in only one copy per $P$. carinii genome [37].

In nine of the patients, a single $P$. carinii sp. f. hominis ITS sequence type was observed in the OP sample taken before the start of treatment. In eight of these patients, the same type was observed in the BAL sample taken 1-3 days later (there was no BAL sample for patient 4), showing a good correlation between ITS sequence type observed in the BAL and OP samples. In OP samples from three patients (patients 1,2 and 9) at day 1 in which more than one ITS sequence type was detected, a more complex picture was observed. Twoto-four different ITS sequence types were observed in the OP sample before the start of treatment and in the BAL sample from these three patients. In each case, one of the types was present in both the OP and BAL samples.

In the majority of patients ( 9 of 12), the ITS sequence type identified before the start of treatment was the same as at the final time point. In these nine patients, a single $P$. carinii sp. f. hominis type was identified in each sample; this suggested $P$. carinii sp. f. hominis strain stability over this time period and a lack of ITS genotype switching during the course of treatment in these patients. In patient 10, ITS sequence typing was performed on four different OP samples during the treatment (days 1, 2, 3 and 10$)$. The same type $\left(B_{1} a_{3}\right)$ was found as a single type in all the samples. In the three patients in whom mixed infections were observed, the data were more complex. In patient 2 , a total of nine different ITS types was found throughout the treatment period. In each patient, one of the ITS sequence types was common to all three samples, taken before the start of treatment, during treatment and at the final time point. Other studies have also reported the lack of clonality in $P$. carinii sp. f. hominis infection showing mixed infection with multiple types of $P$. carinii sp. f. hominis, as demonstrated by polymorphisms at a number of genetic loci $[11,15$, $18,20,21,23,24]$. A total of seven different ITS sequence types has been reported in a sample from Denmark [24].

The ITS sequence types $B_{2} a_{1}$ and $B_{1} a_{3}$ were the most common types found in this study, each observed in five of the 12 patients. These $P$. carinii sp. f. hominis types have also been reported as frequent types in samples from Denmark and the USA (types Ne and Eg respectively) [24]. Two patients in this study had had a previous episode of PCP (patients 7 and 8). The ITS sequence type $B_{2} a_{1}$ was found in the samples from both these patients, giving further support to the original observation that $\mathrm{B}_{2} \mathrm{a}_{1}$ was frequently found in second and subsequent episodes of PCP, and may represent a more persistent or more transmissible type of $P$. carinii sp. f. hominis [20].

This study demonstrated that ITS sequence typing of $P$. carinii sp. f. hominis can be done on non-invasive OP samples. Studies are now in progress to utilise these non-invasive samples for typing at other genetic loci, particularly those that encode the targets of anti- $P$. carinii therapies. The possible emergence of drugresistant strains of $P$. carinii sp. f. hominis has been suggested by the identification of isolates with polymorphisms in the gene encoding dihydropteroate synthase (DHPS), the target of sulphonamide drugs [38-40] and in the gene encoding cytochrome $b$, the target of atovaquone [41]. The use of OP samples for 
sequence typing at these gene targets will greatly facilitate studies on the identification of drug resistance in $P$. carinii sp. f. hominis.

Nested PCR amplifying the mt LSU rRNA from OP samples provides a non-invasive method for monitoring response to treatment of PCP in HIV-infected patients, and permits the analysis of the duration of the infection with different anti- $P$. carinii treatment regimens. ITS sequence typing of $P$. carinii sp. f. hominis from OP samples appears to be a reliable alternative to typing from BAL fluid. This will provide a non-invasive tool for further epidemiological studies, and in particular the correlation of different $P$. carinii sp. f. hominis ITS sequence types with duration of the infection, the association of different ITS sequence types with different treatment regimens and the identification of organisms that demonstrate resistance to anti- $P$. carinii drugs.

This research was supported by the Royal Society (A.E.W.) and the Medical Research Council (A.G.T.). We thank the Oxford Pneumocystis Research Group for helpful discussion.

\section{References}

1. Walzer PD. Perl DP, Krogstad DJ, Rawson PG, Schultz MG. Pneumocystis carinii pneumonia in the United States. Epidemiologic, diagnostic, and clinical features. Ann Intern Med 1974; 80: 83-93.

2. Kovacs JA, Ng VL, Masur H et al. Diagnosis of Pneumocystis carinii pneumonia: improved detection in sputum with use of monoclonal antibodies. $N$ Engl J Med 1988; 318: 589-593.

3. Griffiths MH, Kocjan G, Miller RF, Godfrey-Faussett P. Diagnosis of pulmonary disease in human immunodeficiency virus infection: role of transbronchial biopsy and bronchoalveolar lavage. Thorax 1989; 44: 554-558.

4. Wakefield AE, Pixley FJ, Banerji $\mathrm{S}$ et al. Detection of Pneumocystis carinii with DNA amplification. Lancet 1990; 336: $451-453$.

5. Wakefield AE, Guiver L, Miller RF, Hopkin JM. DNA amplification on induced sputum samples for diagnosis of Pneumocystis carinii pneumonia. Lancet 1991; 337: 13781379.

6. Wakefield AE, Miller RF, Guiver LA, Hopkin JM. Oropharyngeal samples for detection of Pneumocystis carinii by DNA amplification. $Q J$ Med 1993; 86: 401-406

7. Helweg-Larsen J, Jensen JS, Lundgren B. Non-invasive diagnosis of Pneumocystis carinii pneumonia by PCR on oral washes. Lancet 1997; 350: 1363.

8. Helweg-Larsen J, Jensen JS, Benfield T, Svendsen UG, Lundgren JD, Lundgren B. Diagnostic use of PCR for detection of Pneumocystis carinii in oral wash samples. $J$ Clin Microbiol 1998; 36: 2068-2072.

9. Wakefield AE, Pixley FJ, Banerji S et al. Amplification of mitochondrial ribosomal RNA sequences from Pneumocystis carinii DNA of rat and human origin. Mol Biochem Parasitol 1990; 43: 69-76.

10. Wakefield AE. DNA sequences identical to Pneumocystis carinii f. sp. carinii and Pneumocystis carinii f. sp. hominis in samples of air spora. J Clin Microbiol 1996; 34: 1754-1759.

11. Tsolaki AG, Beckers P, Wakefield AE. Pre-AIDS era isolates of Pneumocystis carinii f. sp. hominis: high genotypic similarity with contemporary isolates. J Clin Microbiol 1998 36: $90-93$.

12. Tamburrini E, Ortona E, Visconti E et al. Detection of Pneumocystis carinii in oropharyngeal washings by PCRSHELA and nested PCR. J Eukaryot Microbiol 1997; 44: 48S

13. Lee C-H, Lu J-J, Bartlett MS et al. Nucleotide sequence variation in Pneumocystis carinii strains that infect humans. Clin Microbiol 1993; 31: 754-757.
14. Wakefield AE, Fritscher CC, Malin AS, Gwanzura L, Hughes WT, Miller RF. Genetic diversity in human-derived Pneumocystis carinii isolates from four geographical locations shown by analysis of mitochondrial rRNA gene sequences. $J$ Clin Microbiol 1994; 32: 2959-2961.

15. Keely SP, Stringer JR, Baughman RP, Linke MJ, Walzer PD, Smulian AG. Genetic variation among Pneumocystis carinii hominis isolates in recurrent pneumocystosis. $J$ Infect Dis 1995; 172: 598-598.

16. Banerji S, Lugli EB, Miller RF, Wakefield AE. Analysis of genetic diversity at the arom locus in isolates of Pneumocystis carinii. J Eukaryot Microbiol 1995; 42: 675-679.

17. Lu J-J, Bartlett MS, Shaw MM et al. Typing of Pneumocystis carinii strains that infect humans based on nucleotide sequence variations of internal transcribed spacers of rRNA genes. $J$ Clin Microbiol 1994; 32: 2904-2912.

18. Lu J-J, Bartlett MS, Smith JW, Lee C-H. Typing of Pneumocystis carinii strains with type-specific oligonucleotide probes derived from nucleotide sequences of internal transcribed spacers of rRNA genes. J Clin Microbiol 1995; 33: 2973-2977.

19. Jiang B, Lu J-J, Li B et al. Development of type-specific PCR for typing Pneumocystis carinii f. sp. hominis based on nucleotide sequence variations of internal transcribed spacer regions of rRNA genes. $J$ Clin Microbiol 1996; 34: 32453248 .

20. Tsolaki AG, Miller RF, Underwood AP, Banerji S, Wakefield $\mathrm{AE}$. Genetic diversity at the internal transcribed spacer regions of the rRNA operon among isolates of Pneumocystis carinii from AIDS patients with recurrent pneumonia. $J$ Infect Dis 1996; 174: 141-156.

21. Keely SP, Stringer JR. Sequences of Pneumocystis carinii f. sp. hominis strains associated with recurrent pneumonia vary at multiple loci. J Clin Microbiol 1997; 35: 2745-2747.

22. Latouche S, Ortona $\mathrm{E}$, Mazars $\mathrm{E}$ et al. Biodiversity of Pneumocystis carinii hominis: typing with different DNA regions. J Clin Microbiol 1997; 35: 383-387.

23. Latouche S, Poirot J-L, Bernard C, Roux P. Study of internal transcribed spacer and mitochondrial large-subunit genes of Pneumocystis carinii hominis isolated by repeated bronchoalveolar lavage from human immunodeficiency virus-infected patients during one or several episodes of pneumonia. $J$ Clin Microbiol 1997; 35: 1687-1690.

24. Lee C-H, Helweg-Larsen J, Tang $\mathrm{X}$ et al. Update on Pneumocystis carinii f. sp. hominis typing based on nucleotide sequence variations in internal transcribed spacer regions of rRNA genes. $J$ Clin Microbiol 1998; 36: 734-741.

25. Miller RF, Kocjan G, Buckland J, Holton J, Malin A, Semple SJG. Sputum induction for the diagnosis of pulmonary disease in HIV positive patients. $J$ Infect 1991 ; 23: 5-15.

26. Miller RF, Le Noury J, Corbett EL, Felton JM, De Cock KM. Pneumocystis carinii infection: current treatment and prevention. J Antimicrob Chemother 1996; 37: Suppl B: 33-53.

27. The National Institutes of Health, University of California Expert Panel for Corticosteroids as Adjunctive Therapy for Pneumocystis Pneumonia. Consensus statement on the use of corticosteroids as adjunctive therapy for Pneumocystis pneumonia in the acquired immunodeficiency syndrome. $N$ Engl $J$ Med 1990; 323: $1500-1504$.

28. Tamburrini E, Mencarini P, De Luca A et al. Diagnosis of Pneumocystis carinii pneumonia: specificity and sensitivity of polymerase chain reaction in comparison with immunofluorescence in bronchoalveolar lavage specimens. $J$ Med Microbiol 1993; 38: 449-453.

29. Tamburrini E, Mencarini P, De Luca A et al. Simple and rapid two-step polymerase chain reaction for diagnosis of Pneumocystis carinii infection. J Clin Microbiol 1993; 31: 2788-2789.

30. Wakefield AE, Miller RF, Guiver LA, Hopkin JM. Granulomatous Pneumocystis carinii pneumonia: DNA amplification studies on bronchoscopic alveolar lavage samples. $J$ Clin Pathol 1994; 47: 664-666.

31. De Luca A, Tamburrini E, Ortona E et al. Variable efficiency of three primer pairs for the diagnosis of Pneumocystis carinii pneumonia by the polymerase chain reaction. Mol Cell Probes 1995; 9: 333-340.

32. Tamburrini E, Mencarini $\mathrm{P}$, Visconti $\mathrm{E}$ et al. Comparison of two PCR methods for detection of Pneumocystis carinii in bronchoalveolar lavage fluid. J Eukaryot Microbiol 1996; 43. $20 \mathrm{~S}$. 
33. Weig M, Klinker H, Bögner BH, Meier A, Gross U. Usefulness of PCR for diagnosis of Pneumocystis carinii pneumonia in different patient groups. J Clin Microbiol 1997; 35: $1445-$ 1449.

34. Weig $\mathrm{M}$, Klinker $\mathrm{H}$, Wilhelm $\mathrm{M}$, Lemmer $\mathrm{K}$, Gross $\mathrm{U}$ Correlation of Pneumocystis carinii PCR with clinical diagnosis in immunocompromised patients. Lancet 1996; 347: 1266.

35. Evans R, Ho-Yen DO. Non-invasive diagnosis of Pneumocystis carinii pneumonia. Lancet 1998; 351: 218.

36. Colangelo G, Baughman RP, Dohn MN, Frame PT. Follow-up bronchoalveolar lavage in AIDS patients with Pneumocystis carinii pneumonia. Pneumocystis carinii burden predicts early relapse. Am Rev Respir Dis 1991; 143: 1067-1071.

37. Giuntoli D, Stringer SL, Stringer JR. Extraordinary low number of ribosomal RNA genes in P. carinii. $J$ Eukaryot Microbiol 1994; 41: 88S.

38. Lane BR, Ast JC, Hossler PA et al. Dihydropteroate synthase polymorphisms in Pneumocystis carinii. J Infect Dis 1997; 175: $482-485$.

39. Kazanjian P, Locke AB, Hossler PA et al. Pneumocystis carinii mutations associated with sulfa and sulfone prophylaxis failures in AIDS patients. AIDS 1998; 12: 873-878.

40. Mei Q, Gurunathan S, Masur H, Kovacs JA. Failure of cotrimoxazole in Pneumocystis carinii infection and mutations in dihydropteroate synthase gene. Lancet 1998; 351: 1631-1632.

41. Walker DJ, Wakefield AE, Dohn MN et al. Sequence polymorphisms in the Pneumocystis carinii cytochrome b gene and their association with atovaquone prophylaxis failure. $J$ Infect Dis 1998; 178: 1767-1775. 